\title{
FROM THE ORGANIZING COMMITTEE OF THE INTERNATIONAL WORKSHOP "AQUEOUS SOLUTIONS: THE PROBLEMS OF RADIOACTIVE IMPURITIES"
}

(Lviv, December 7-8, 1996)

This issue of Condensed Matter Physics contains contributed papers submitted to the International Workshop "Aqueous solutions: the problems of radioactive impurities" and accepted by the Organizing Committee. The Workshop was held at the Institute for Condensed Matter Physics in Lviv on December 7-8, 1996. There were participants from the Ministry of Environmental Protection and Nuclear Safety of Ukraine, the Ministry on Emergency Situations of Ukraine, the Chornobyl center, the "Shelter" object, the Interdisciplinary Scientific and Technical Center "Shelter", the State Specialized Enterprise "Technocenter", the Institute for Condensed Matter Physics, the Institute for the Problems of Mathematical Devices and Systems, the Institute of Physics and Mechanics and Lviv State University.

The Workshop was organized by the Institute for Condensed Matter Physics of the National Academy of Sciences of Ukraine and the International center "Science and Industry" due to the promotion of the International Fund "Vidrodzhennya", the International Scientific Fund and the West-Ukrainian Fund for Science Support.

The subject of the Workshop comprised questions concerning the present state of the "Shelter" object, the problem of water in it, disintegration of the construction materials under the radiation effects, indoor and outdoor radionuclide transport.

Representatives of the "Shelter" object (E.L.Belousov), Chornobyl center (V.M.Glygalo), Interdisciplinary Scientific and Technical Center "Shelter" (O.P.Krinicyn, K.P.Checherov), Enterprise "Technocenter" (S.B.Kumshaev, M.S.Khodorovski), Ministry of Environmental Protection (K.G.Rudya), Ministry on Emergency of Ukraine (P.I.Korchagin) presented information about the state, content and distribution of nuclear fuel in the "Shelter" object, the physical and chemical state of fuel containing materials, lava-like masses, the content and distribution of water in the "Shelter", the state of construction materials in it, prediction of the nuclear fuel behaviour and measures to be taken to increase the "Shelter" safety. Representatives of the Institute for Condensed Matter Physics of the National Academy of Sciences of Ukraine (M.V.Tokarchuk, M.F.Holovko) and of the P. \& M.Curie University (J.-P.Badiali) considered fundamental aspects of the water interaction with fuel containing materials, analysed the processes of radiolysis, hydrolysis, complex formation and polymerization of radioactive elements in aqueous solutions. In reports from the Institute for the Problems of Mathematical Devices and Systems (M.I.Zheleznyak, E.L.Kivva) models for the 
radionuclide transport in the ground water under the "Shelter" object and outside it were considered. Researchers from the Institute of Physics and Mechanics of the National Academy of Sciences of Ukraine (V.V.Panasyuk, O.E.Andreikiv, V.I.Pokhmurski) discussed the problems of metal and construction materials disintegration in the presence of the hydrogen and radiation effect.

Within the framework of the Workshop a general discussion "Problems of the "Shelter" stabilization connected with water. Fundamental aspects and practical ways of their solution" took place under the chairmanship of the Deputy Chief of the Commission on Science and Education of the Parliament of Ukraine, director of the Institute for Condensed Matter Physics academician of the National Academy of Sciences of Ukraine I.R.Yukhnovskii and Minister of Environmental Protection and Nuclear Safety of Ukraine Yu.I.Kostenko.

The following conclusions were drawn at the Workshop:

- At present there is broad information about the "Shelter" object which is, however, unsystematised and kept primarily on paper.

- The available information is not complete and does not enable us to draw conclusions about the real physical and chemical state of the object, in particular there are contradictory estimates as to the content and distribution of nuclear fuel in the "Shelter", its geometry and localization of active core fragments after the accident, the content and behaviour of the water in the object.

- Experts report about $1000 \mathrm{~m}^{3}$ of water coming to the "Shelter" every year. According to the Chornobyl nuclear power plant data, there is near $3000 \mathrm{~m}^{3}$ of water inside the object, of which only one third is under control. What becomes of the water excess is an open question.

- Interaction of irradiation products with water during radiolysis and hydrolysis intensively produces atomic hydrogen penetrating into the solid medium. Hydrogen molization results in an extreme rise of the gas pressure that disintegrates fuel containing masses and construction materials. Then the contact surface with water increases, so disintegration is accelerated. By this strategy an uncontrolled outflow of uranium, plutonium, cesium, strontium is stimulated from the glassy matrix into the aqueous basins of the object.

- One has to distinguish alkaline, alkaline-earth ions and actinides among the radioactive particles. Ions of actinides possess high valency. Their behaviour differs qualitatively from that of ions of the first and second type: actinides form a network due to groups $\mathrm{OH}^{-}$. So there is an actual task of studying polymerization and complex formation in aqueous solutions of active elements, as well as the growth 
of minerals able to increase active elements local concentration and, therefore, an effective neutron multiplication factor.

- Swelling is an important mechanism of construction elements disintegration. $(n, \alpha)$-reactions produce a considerable amount of atomic helium, that results in the swelling of materials and their further destruction.

- Experimental measurements (Interdisciplinary Scientific and Technical Center "Shelter") reveal a rise in the concentration of strontium and cesium in boreholes of the object industrial territory. It can be connected with the "block" water penetration into the ground outside the object. One of main reasons for radioactive ionic transport from the Chornobyl zone is an interaction between the environment moistened by ground waters and the dry radioactive ground of the "Shelter" object. Here diffusion processes are determined not only by the gradients of concentrations, but also by electrostatic effects which have not been considered so far.

- Radionuclide transport in the surface waters of the system "water pumping of the Chornobyl plant nearby zone - the river Prypjat - the cascade of the Dnieper reservoirs" is one of the main ways of radionuclide migration from the plant region. An accident in the "Shelter" can result in heavy radiation consequences for the Dnieper watershed population.

On the basis of these conclusions the Workshop participants put forward the following proposals and recommendations:

- The existing programmes for studying the real situation in the "Shelter" object must be supplemented by corrections aimed at the systematic collection of information and elaboration of a modern software for its processing and access to information sources. It is worthwhile organizing a central informational center to compose a universal database about the "Shelter" object.

- It is appropriate to organize a group of independent experts involving scientists from world scientific centers to verify the information and to correct research programs.

- It makes sense to study the question of fuel containing masses disintegration at their contact with water and acceleration of the active elements inflow into water in order to utilize active wastes.

- It is advantageous to research on the problem of aqueous solutions with radioactive ions taking into account their interaction with fuelcontaining materials. Ways of their disintegration and active isotope inflow into water should be emphasized. 
- It is necessary to carry out research aimed at the diffusion and penetration of hydrogen into construction and fuel containing materials, the formation of helium and its piling up, as well as other impurities accelerating disintegration. Due attention should be given to the aspects of material longevity and mechanisms affecting the destruction rate.

- It is necessary to stimulate studies on the "block" water penetration into the ground outside the "Shelter" object and radionuclide transport from the Chornobyl plant adjoining zone.

- It is important to study diffusion and osmosis in the systems "active elements aqueous solutions - clayey ground" to determine the efficiency of clayey filters and burials of radioactive wastes.

- It is worth improving the monitoring in the vicinity of the object and the development of prediction models for radionuclide transport in the ground, surface waters and atmosphere.

- It is necessary to inform the state authorities about the Workshop results. It would be sensible to hold Workshops on Chornobyl problems in Lviv every two years.

This issue includes papers of a wide scope: from fundamental aspects of problems of water interaction with fuel containing materials to practical recommendations how to convert the "Shelter" object into an environmentally safe one, as well as the problems of informational resources in this area.

The authors of the papers had a possibility to present their own seeing and understanding of the above problems which do not always coincide with the generally accepted ones.

The Organizing Committee would like to express gratitude to the Editorial Board of Condensed Matter Physics for the given possibility to publish the materials of the Workshop in this journal. We hope that this issue will be of interest to those scientists and engineers who deal with the problems of aqueous solutions with radioactive impurities, as well as general problems of the "Shelter" object.

Lviv, November 1997

I.Yukhnovskii,

M.Holovko,

O.Ivankiv,

I.Mryglod,

I.Protsykevytch,

M.Tokarchuk 